\title{
MULHERES PORTADORAS DE TROMBOFILIA: ENTRE NARRATIVAS DA REPRODUÇÃO ASSISTIDA MANDATÓRIA E DA TRAGÉDIA RELACIONADA AOS ANTICONCEPCIONAIS HORMONAIS
}

\author{
DANIELLE RIBEIRO DE MORAES \\ ANA PAUla PEREIRA DA GAMA AlVES RIBEIRO \\ LUIS DAVID CASTIEL
}

\begin{abstract}
RESUMO
Este trabalho sistematiza impressões sobre questões que rondam o diagnóstico e a vivência, em mulheres, de um conjunto de condições médicas denominadas de "trombofilias". Fundamenta-se na experiência da primeira autora e em seus relatos de cunho autoetnográfico, na análise crítica da literatura acadêmica sobre a temática e em observações realizadas pelos autores, ao longo dos últimos 5 anos, de postagens em grupos de portadores de trombofilias, da rede Facebook, voltados ao apoio mútuo de seus componentes. Os resultados apresentados revelam mecanismos de medicalização e controle do corpo feminino desvelados pelas especificidades das portadoras dessas condições. Esses mecanismos estão relacionados à banalização do uso de contraceptivos de base hormonal e à baixa autonomia feminina quanto à escolha de métodos contraceptivos; além disso, revelam barreiras ao acesso a tecnologias de reprodução assistida e a manutenção do papel feminino de reprodução biológica, frente aos problemas de fertilidade relatados.
\end{abstract}

PALAVRAS-CHAVE

Trombofilia; Gênero; Atenção à saúde; Saúde.

WOMEN WITH THROMBOPHILIA BETWEEN NARRATIVES OF MANDATORY ASSISTED REPRODUCTION AND THE TRAGEDY RELATED TO HORMONAL CONTRACEPTIVES

\begin{abstract}
In this paper, we systematize impressions about issues surrounding the diagnosis and experience, in women, of a set of medical conditions known as "thrombophilias". It is based on the experience of the first author and her self-ethnographic reports, on the critical analysis of academic literature on the subject, and on observations made by the authors, over the last 5 years, of postings in Facebook, inside groups of patients with thrombophilia, focused on the mutual support of its components. The results reveal mechanisms of medicalization and control of the female body unveiled by the specificities of the carriers of these conditions. These mechanisms are related to the trivialization of the use of hormonal contraceptives and low female autonomy regarding the choice of contraceptive methods. In addition, they reveal barriers to accessing assisted reproduction technologies and maintaining the female role of biological reproduction in the face of reported fertility problems.
\end{abstract}

KEYWORDS

Thrombophilia; Gender; Health care; Health; 


\title{
FEMMES ATTEINTES DE THROMBOPHILIE: ENTRE NARRATIVES DE LA PROCRÉATION MÉDICALEMENT ASSISTEE OBLIGATOIRE ET LA TRAGÉDIE LIÉE AUX CONTRACEPTIFS HORMONAUX
}

\begin{abstract}
RÉSUMÉ
Dans cet travail sont systématiseés les impressions sur les problèmes liés au diagnostic et à l'expérience vécue par les femmes d'un ensemble de conditions médicales appelées «thrombophilies». Il s'appuie sur l'expérience de la première auteure et de ses propres rapports auto-ethnographiques, sur l'analyse critique de la littérature spécialiseé et sur les observations faites par les auteurs au cours des 5 dernières années d'affichage dans des groupes de personnes atteints de thrombophilie en Facebook, destinés au soutien mutuel de ses composants. Les résultats révèlent des mécanismes de médicalisation et de contrôle du corps féminin dévoilés par les spécificités des porteurs de ces affections. Ces mécanismes sont liés à la banalisation de l'utilisation des contraceptifs hormonaux et à la faible autonomie des femmes en ce qui concerne le choix des méthodes de contraception. En outre, ils révèlent des obstacles à l'accès aux technologies de procréation médicalement assistée et au maintien du rôle féminin de la reproduction biologique face aux problèmes de fertilité signalés.
\end{abstract}

\section{MOTS-CLÉS}

Thrombophilie; Genre; Soins de santé; Santé.

\section{MUJERES CON TROMBOFILIA: ENTRE NARRATIVAS DE REPRODUCCIÓN ASISTIDA OBLIGATORIA Y LA TRAGEDIA RELACIONADA CON LOSANTICONCEPTIVOS HORMONALES}

\begin{abstract}
RESUMEN
Este documento sistematiza las impresiones sobre los problemas relacionados con el diagnóstico y la experiencia en mujeres de un conjunto de afecciones médicas llamadas "trombofilias". Se basa en la experiencia de la primera autora y sus informes autoetnograficos, en el análisis crítico de la literatura académica sobre el tema y en las observaciones realizadas por los autores, en los últimos 5 años, de publicaciones en grupos de pacientes con trombofilia, de Facebook, enfocado en el apoyo mutuo de sus componentes. Los resultados presentados revelan mecanismos de medicalización y control del cuerpo femenino revelados por las especificidades de los portadores de estas afecciones. Estos mecanismos están relacionados con la trivialización del uso de anticonceptivos hormonales y la baja autonomía femenina con respecto a la elección de los métodos anticonceptivos. Además, revelan barreras para acceder a las tecnologías de reproducción asistida y mantener el papel femenino de la reproducción biológica frente a los problemas de fertilidad reportados.
\end{abstract}

\author{
PALABRAS CLAVES \\ Trombofilia; Género; Cuidado de la salud; Salud.
}




\section{INTRODUÇÃO}

Este é um esforço preliminar de sistematização de impressões sobre algumas questões que verificamos rondarem o diagnóstico e a vivência, em mulheres, de um conjunto de condições médicas denominadas de "trombofilias" tanto pela formação de médica sanitarista e generalista da primeira autora, pesquisadora que se dedica a investigações sobre moralização, discurso médico e apropriações do conceito de risco pelo campo da saúde, quanto por sua condição de mulher portadora de trombofilia hereditária. Os demais autores apoiam essas primeiras aproximações a partir da inserção como antropóloga, no caso da segunda autora; e, o terceiro autor, como médico que tem se dedicado à pesquisa sobre risco em saúde.

Este texto fundamenta-se na experiência da primeira autora e em seus relatos de cunho autoetnográfico, da análise crítica da literatura acadêmica sobre a temática e das observações de postagens em grupos de portadores de trombofilias, da rede Facebook, voltados ao apoio mútuo de seus componentes. Apesar de alguns dos grupos contarem com um número expressivo de membros, alguns deles são fechados e, portanto, por cuidado ético preferimos não expor especificidades, tampouco localizar membros ou excertos de seus posts. Em seu lugar, descrevemos impressões gerais e comuns ao conjunto geral das observações realizadas ao longo dos últimos 5 anos, que reverberaram seja em páginas públicas da rede, seja na mídia impressa, conforme se verá a seguir.

Abrimos espaço para explicitarmos a forma com que o texto se apresenta, coadunando-se ao conteúdo, ancorada numa dimensão metodológica que aciona a implicação da autoria na construção do objeto de pesquisa. Desta maneira, entendemos ser importante mencionar que utilizaremos a "pessoa da língua" de forma diversa ao longo dos trechos: uma primeira pessoa do singular que localiza explicitamente a experiência da primeira autora, ao longo do relato de cunho autoetnográfico que apoia empiricamente este texto; e uma segunda pessoa do plural, quando desejamos sinalizar que, ao material empírico, os autores fazem sua abordagem analítica conjuntamente.

"Trombofilia" é uma predisposição aumentada a tromboembolismo, devida a fatores genéticos ou adquiridos (GUIMARÃES et al., 2009). Dito de outro modo, trombofilias são um conjunto de condições de saúde caracterizadas pelo risco aumentado de situações potencialmente fatais, chamados "eventos trombóticos". Devido a mecanismos de coagulação alterados, várias doenças são comumente associadas a esses eventos, para os

\footnotetext{
${ }^{1}$ Esta é uma ampliação modificada de comunicação da II Reunião de Antropologia da Saúde e parte do projeto de pesquisa em curso denominado "Trombofilia e Mulheres: entre as marcas de gênero, a mercantilização da vida e os direitos reprodutivos".
} 
quais as pessoas com diagnóstico de trombofilia têm maior probabilidade de ocorrência. Citam-se: tromboses venosas e arteriais, embolia pulmonar, acidente vascular cerebral, infarto agudo do miocárdio, entre outros.

Quando as trombofilias ocorrem em mulheres, além dos eventos descritos, destacase o risco aumentado de perdas gestacionais recorrentes e de outras intercorrências durante a gravidez e o puerpério. O diagnóstico de trombofilia é, então, uma causa comum de busca por tecnologias de reprodução assistida (TRA) na chamada "clínica de infertilidade" (SILVA SOLIGO et al, 2007). Ainda, o uso de contraceptivos de base hormonal (CBH - também chamados de anticoncepcionais) em mulheres trombofílicas funciona como um fator de risco somado à condição de base, aumentando ainda mais a probabilidade de eventos trombóticos. Considera-se, de modo geral, que os CBH são contraindicados para mulheres portadoras de trombofilia.

Apesar disso, na literatura médica são frequentes os casos de eventos trombóticos fatais ou incapacitantes em trombofílicas não diagnosticadas que utilizavam esses medicamentos (POLITI et al., 2013). Amputações, cirurgias vasculares complexas decorrentes de tromboses venosas amplas, lesões neurológicas permanentes e morte por embolia pulmonar não são infrequentes ao observarmos também relatos de grupos de ajuda mútua de trombofílicos em redes sociais e na mídia impressa (REVISTA ÉPOCA, 2015).

Apesar de sua considerável distribuição na população - estima-se que o Fator $V$ de Leiden, considerada a trombofilia hereditária mais prevalente, atinja cerca de 5 a 7\% da população caucasiana estadunidense (IHTC, 2017) -, constituem ainda condições pouco diagnosticadas e cujo conhecimento é pouco difundido. Avalia-se que o conhecimento clínico e as repercussões sociais do diagnóstico das trombofilias necessite ser melhor divulgado entre as especialidades médicas mais ligadas à atenção primária em saúde, que habitualmente não se deparam com o acompanhamento especializado dos eventos trombóticos (MANN, 2003; BANK, 2004).

Sendo um tema de debate candente na literatura biomédica, até o momento não se considera imperativa a ampla testagem de rastreamento para trombofilias (VERNON; HIEDEMANN; BOWIE, 2017). Ainda que o dispendioso screening laboratorial obedeça a um rol de indicações específicas, há protocolos de identificação de fatores de risco para eventos trombóticos a serem utilizados quando da opção clínica de algum medicamento que aumenta o risco desses eventos, sobretudo os CBH (LIMA; BORGES, 2012). Desta forma, se por um lado a indicação de testagem para o diagnóstico de trombofilias é restrita a determinadas situações, por outro lado, uma avaliação criteriosa de possível risco aumentado para eventos trombóticos, a partir da coleta cuidadosa da história clínica (anamnese), se impõe. 
Trata-se de uma problemática a ser enfrentada pelos sistemas de saúde, se levarmos em conta que os CBH são amplamente utilizados, e que não são apenas indicados para contracepção, mas têm tido seu uso ampliado para outras condições clínicas, como a síndrome de ovários policísticos. Ainda, medicamentos de base hormonal análoga têm sido amplamente usados na menopausa e síndrome climatérica, sob o nome de "terapia de reposição hormonal". Além disso, a terapia hormonal é uma das bases da redesignação de gênero, o que pode acarretar riscos acrescidos às pessoas transgênero que sejam eventualmente trombofílicas.

Podemos considerar que, dado o amplo uso de CBH e a magnitude de ocorrência de eventos trombóticos entre mulheres trombofílicas, potenciais usuárias desses medicamentos, são cabíveis reflexões tanto sobre as estratégias de difusão de conhecimento voltadas a essa problemática entre o público feminino, quanto sobre as marcas de gênero que rondam a questão. Isso porque a escolha do método contraceptivo é muitas vezes orientada por desigualdades de gênero, que têm como uma de suas características a naturalização da manipulação e medicalização do corpo feminino. Essa face dos processos de medicalização é fulcral para a produção e reprodução de desigualdades sociais, nas sociedades capitalistas (GIFFIN, 2002; VIEIRA, 2003; COSTA et al., 2006; HIRATA; KERGOAT, 2007).

Essa problemática, quando acrescida da parca difusão do conhecimento - entre profissionais de saúde e público leigo - sobre as trombofilias, implica na impossibilidade de abordagens integrais em saúde, conforme previsto entre as diretrizes e as orientações programáticas do Sistema Único de Saúde (BRASIL, 2004). Circunscrevendo essa questão ao Brasil, uma breve observação sobre o número de estudos publicados sobre esta temática aponta para uma possível lacuna na produção de conhecimento.

Na segunda quinzena de dezembro de 2018, ao buscar pelo termo "trombofilia" entre os periódicos da biblioteca eletrônica Scielo Brasil, sem utilizar quaisquer filtros de campo, foram recuperadas somente 61 referências. Ao combinar "trombofilia" com o termo "gênero", houve recuperação de apenas uma referência cujo enfoque, no entanto, não aborda essa questão. Possivelmente, há produções de autores de afiliação institucional brasileira em outras bases de recuperação de referências ${ }^{2}$ mas, de todo modo, esse breve mapeamento mostra a exiguidade de estudos sobre a temática em língua portuguesa, que podem funcionar melhor para divulgar informações, seja facilitando o advocacy, seja para subsidiar a formulação de políticas públicas no Brasil.

\footnotetext{
${ }^{2}$ Do mesmo modo e no mesmo período, ao realizarmos buscas análogas na base Scopus, conhecida pela amplitude de fontes e periódicos e da abrangência de áreas de conhecimento e regiões de publicação, obtivemos resultados semelhantes. A análise discursiva dessa produção está sendo desenvolvida no âmbito do projeto citado anteriormente.
} 


\section{"GENTE, PEGUEI MEU TESTE": TROMBOFILIAS, ATENÇÃO À SAÚDE E A RELAÇÃO COM 0 RISCO A PARTIR DE UM RELATO PESSOAL}

Nesta seção faço um relato pessoal que revela uma marca de afiliação teórica pelo processo situado de conhecimento acadêmico (HARAWAY, 1991). E, distinguindo-se do que tenho percebido nesta trajetória de pesquisa como fala dominante do corpo feminino, tratase também de uma revelação política de um corpo que se situa como passível de ser falado para além da função reprodutiva, aos moldes das epistemologias feministas (BERMAN, 1997).

Como mencionei, apesar de eu ter ao menos dois tipos de trombofilias hereditárias, meu diagnóstico ocorreu, no entanto, somente há cerca de 5 anos, após um dos vários episódios trombóticos que tive ao longo da vida. Portanto, essas impressões remontam ao início de 2013. No episódio mencionado, apresentei mais um dentre os vários ataques isquêmicos transitórios (AIT) que tive antes de iniciado o tratamento por tempo indeterminado com anticoagulantes. Diferentemente dos demais episódios, tive minhas queixas clínicas valorizadas, o que permitiu uma breve e protocolar internação numa unidade de cuidados intensivos (UTI) num hospital da rede suplementar do estado do Rio de Janeiro.

A distinção desta abordagem para as demais foi que, desta vez, e escapando ao "protocolo para AIT", o médico plantonista permitiu uma anamnese prolongada, que começou com a assertiva: "mas me conte sobre a sua vida". Apesar de ser um procedimento que deveria ser habitual para casos como este, a abertura para investigar tal "caso atípico" desta maneira tem perdido força no meio médico, sobretudo após as inflexões que a racionalidade da protocolização impôs à prática clínica (CASTIEL; PÓVOA, 2002).

Ele me perguntou se eu tinha ou não filhos, ao que respondi que não, e se eu usava contraceptivos orais. Ele se impressionou que, mesmo com 39 anos, eu não tivesse feito uso desses medicamentos. Quando me perguntou o porquê de não usar anticoncepcionais, respondi que utilizava preservativos, pois para mim se tratava de uma tomada de posição política feminista. Falamos brevemente sobre gênero e ele achou interessante meu interesse nesta área. Ainda, me perguntou se alguma vez eu havia ficado grávida, ao que respondi que "não que eu soubesse", pois não havia realizado nenhum aborto até então. Perguntou por que eu não tinha tido filhos e eu disse que, apesar de ter um companheiro de longa data, a maternidade, por sua via biológica, nunca fora para mim um desejo.

Após me pedir licença para estudar na sala anexa, o jovem, bem-humorado e atencioso médico retornou e me perguntou, então, se eu "toparia" fazer um conjunto de exames de rastreamento para trombofilias. Antes, porém, ele quis se certificar de que eu estava ciente dos possíveis desdobramentos dos resultados desses exames. Na minha 
cabeça, veio um conjunto de diagnósticos diferenciais e me lembrei, ao longe, dos compêndios de doenças hematológicas que já havia estudado, atendo-me às possibilidades de suas consequências físicas. Imaginei que talvez nem fosse o caso de eu ter um problema hematológico, mas entendi, naquele momento, que se fosse o caso, melhor seria sabê-lo. Mencionei que estava ciente sem, no entanto, atentar justamente para as implicações de gênero envolvidas no diagnóstico. Ora, os compêndios médicos geralmente não mencionam as desigualdades de gênero como tais. E, afinal, a fragilidade da vivência de uma internação em UTI trazia a dimensão de finitude que não me permitiu, àquela altura, imaginar que minha vida seria atravessada por essas questões.

A alta da UTI veio no dia seguinte, com o médico chefe do setor chamando minha mãe e meu marido (também médico) à época para insinuar que talvez não se tratasse de um AIT, apesar da hipótese de trombofilia, levantada pelo colega que me atendeu ao longo da madrugada e o que ele, curiosamente, não mencionou. Minha queixa era "somente" de dormência na face, um sintoma que, no entanto, como é comum nesses casos, não teria respaldo em exames de imagem. Portanto, ele teria de acreditar na minha queixa e, assim, seria obrigado a realizar o restante da investigação protocolar de eventuais danos neurológicos. O chefe da UTI estava visivelmente contrariado e esta abordagem repetiu as anteriores ao meu diagnóstico: insinuações de que eu estaria "querendo chamar a atenção", "coisa de mulher histérica", "coisa de filha única", coisa de "filho de "pais não casados", "caso para a psiquiatria", modos de explicar esses episódios que eu ouvi em diferentes momentos da vida. Afinal, minhas limitações neurológicas sempre foram, por sorte, passageiras.

Pois alguns dias depois, a "coisa de mulher histérica" tomou a forma de um conjunto de letras marcadas no papel do resultado dos dispendiosos exames de mapeamento genético que mostravam que eu era portadora de uma trombofilia hereditária, chamada Fator $V$ de Leiden (FVL). Soube depois, tendo voltado ao hospital para agradecer ao médico que supôs o diagnóstico, que meu "caso" tinha sido escolhido para ser estudado, possivelmente numa atividade comum no ethos médico, chamado sessão clínica.

De minha parte, como indicado, recorri a um colega conhecido, médico especialista em doenças do sangue (hematologista), que teve o desprazer, reportado por ele, de instituir para mim o tratamento, por tempo indeterminado, com anticoagulantes ${ }^{3}$. A escolha de qual anticoagulante oral usar traz, em si, uma disputa relacionada ao apelo de grandes laboratórios pela popularização de medicamentos mais caros e recentes (MORAES, 2016).

\footnotetext{
3 Nem todas as pessoas diagnosticadas com trombofilias necessitam de tratamento com anticoagulantes. De outro modo, esses medicamentos são também indicados em outras condições chamadas de hipercoagulabilidade, em que há maior risco de trombose ou embolia, como em portadores de próteses cardíacas e para tratamento de episódios de embolia pulmonar e trombose venosa profunda, por exemplo.
} 
Apesar de considerar ser esta disputa um caso emblemático para estudarmos medicalização, não trataremos disto neste trabalho.

O anticoagulante que escolhemos juntos (o hematologista e eu) - a warfarina - é um remédio relativamente barato, disponível há tempos no mercado e também no Sistema Único de Saúde (SUS). No entanto, seu uso requer alguns cuidados com a alimentação (vegetais verdes e outros alimentos ricos em vitamina $\mathrm{K}$ reduzem sua atuação). Além disso, necessita de monitoramento, através de exames de sangue, de índices relacionados ao processo de coagulação, possui efeitos colaterais de longo prazo que podem incluir cansaço intenso, queda de cabelos e maior tendência à osteoporose. É comum que as pessoas usuárias fiquem com o corpo marcado de manchas roxas (hematomas), pela tendência a hemorragias, o que requer um estado de alerta permanente aos possíveis sinais de hemorragias em órgãos internos. Sua principal vantagem é que, além de ser barato, seu efeito é facilmente revertido em caso de acidentes, por exemplo, em que é necessário reduzir o tempo de sangramento. Por fim, seu uso é reconhecidamente teratogênico e, portanto, não é indicado a mulheres em tentativa de engravidar, ou grávidas, consumirem warfarina ou outros anticoagulantes orais, pelo risco de dano ao feto e a possibilidade de problemas ao nascer.

Frente a todas essas questões e a outros problemas crônicos de saúde que eu apresento, decidi que não teria filhos por via biológica o que foi, inclusive, fortalecido em outras consultas médicas, com diferentes especialistas. No entanto, como vim a perceber posteriormente que é comum, iniciaram-se conflitos, a partir desta decisão, entre mim e meu marido à época, o que culminou com um divórcio, dois anos depois. Na época do diagnóstico estava então escrevendo minha tese de doutoramento, licenciada do trabalho, e lidando com as mudanças no cotidiano que o diagnóstico e o tratamento da trombofilia interpunham, além da crise conjugal cujo estopim residia na minha negação do naturalizado "papel feminino" de mãe biológica.

Além de fazer sessões periódicas de psicanálise há vários anos, uma saída para este enfrentamento foi participar de grupos no Facebook, voltados ao suporte mútuo de portadores. Buscando lidar com o sofrimento que o diagnóstico impunha, o que inclui sintomas e sinais corporais cuja lida cotidiana não é pauta dos tratados médicos, passei a tomar parte de grupos em inglês que tematizavam minha trombofilia diagnosticada (FVL), e também grupos de usuários de warfarina. Percebi que, à época, não havia grupos em português sobre o FVL e criei um, sendo hoje não mais uma de suas administradoras. Mais adiante, a segunda autora deste trabalho também passou a participar desse tipo de grupo e a observar os fenômenos aqui relatados.

Atribuo à minha participação nos grupos muito da ajuda ao lidar com o diagnóstico e com as dúvidas sobre a condição/doença (essa enunciação da trombofilia ora como doença, 
ora como condição médica não é um consenso nos grupos) que não constam dos manuais médicos e que se relacionam com o cotidiano de portadores e sua potência de geração de autonomia frente a questões de saúde. Muitas vezes, as primeiras postagens de mulheres nos grupos têm mensagem análoga ao título desta seção: "gente, peguei meu teste", seguida de um pedido de ajuda: "alguém sabe o que isso quer dizer?".

Esse caminho de reconhecimento de um corpo ao mesmo tempo diverso, ou não previsto pelos processos de medicalização no sentido da afirmação da reprodução biológica; e, por outro lado, tão amplamente medicalizado e convergente com a perspectiva preemptiva relacionada com medicamentos que "tratam" o risco de adoecer (com o uso de anticoagulantes), fez-me identificar, como pesquisadora e sujeito da pesquisa, com os apagamentos epistêmicos que depreendemos de Berman (1997). Neste caso, apagando-se o sofrimento gerado pelas marcas corporais, por um corpo feminino diverso, maduro, não reconhecidamente situado nos discursos hiperpreventivos, seja pela pretensa "пão adequação reprodutiva", seja por sua modificação estética e dolorosa.

Ao mesmo tempo em que fazia esta pesquisa, crescia o medo de enfrentar a inadequação e escrever sobre a experiência, tornando-a um objeto transgressor ao próprio campo ao qual pertenço (SÁNCHEZ, 2008; MORAES, 2016). Mas, como tomada de posicionamento político feminista, chegou o tempo de escrevê-lo e tentar publicá-lo, utilizando-me da perspectiva autoetnográfica também como modo de resistência (como em DUTRA, 2018).

Além disso, podemos perceber pontos de convergência entre as marcações de gênero de meu relato com o que vimos observando nos grupos, entre as quais, muitas questões que se colocam em torno da reprodução biológica, enunciada nos grupos, majoritariamente, como um atributo eminentemente feminino. Essas questões se apresentam desde como dilemas acerca da contracepção, até os processos da vivência da maternidade em portadoras de trombofilias. Buscamos sistematizá-las brevemente a seguir.

\section{CORPOS FEMININOS, TROMBOFILIA E REPRODUÇÃO NO FACEBOOK: DUAS VIAS NARRATIVAS}

\section{A PRIMEIRA ENTRADA: A VIA TRÁGICA DOS ANTICONCEPCIONAIS ORAIS}

Nos grupos acompanhados ${ }^{4}$, é comum que as mulheres participem com um número maior de postagens que os homens. Dependendo do grupo, as narrativas mostrarão o

\footnotetext{
${ }^{4}$ As observações aqui descritas são fruto da participação da primeira e da segunda autoras como membros de grupos de Facebook relacionados tanto a trombofilias específicas, como o próprio Fator $\mathrm{V}$ de Leiden, quanto voltados às questões reprodutivas envolvidas no diagnóstico de trombofilia. Não foi informado nos grupos, pela autoria, a realização da pesquisa, ainda que outras pessoas tenham já postado nos grupos em português chamadas para outras pesquisas. No entanto,
} 
caminho pelo qual o/a participante chegou até ali. De modo geral, as mulheres recorrem aos grupos após receberem o diagnóstico de trombofilia, através de uma dentre duas vias principais: a) a ocorrência de um problema grave de saúde, muitas vezes relacionado com o uso de contraceptivos de base hormonal; b) uma ou mais perdas gestacionais atribuídas à trombofilia.

Na primeira via, os grupos dedicados ao enfrentamento e suporte mútuo de eventos trombóticos graves, como trombose venosa profunda, e os grupos de usuários de warfarina apresentam geralmente uma narrativa trágica, com um número maior de relatos sobre o diagnóstico de trombofilia realizado após esses eventos graves, como embolias pulmonares, tromboses, derrames e infarto do miocárdio. São comuns relatos sobre perdas abruptas de familiares, várias das vezes jovens, ou relatos pessoais e fotografias que refletem diferentes graus de restrições cotidianas ${ }^{5}$, principalmente de membros inchados, de manchas roxas ou outros sinais de hemorragias.

Como mencionado, se a trombofilia é uma condição que traz o risco de eventos trombóticos (ou seja, em que a formação de coágulos mais rápida ou mais frequentemente que o habitual é um problema), naqueles casos em que se estabelece o tratamento do risco de trombose com anticoagulantes, os portadores se deparam com o aparente paradoxo de terem risco de hemorragias. Essa guinada na relação com o risco é em geral de difícil compreensão, e leva a inúmeras postagens sobre dúvidas a esse respeito e à problemática do que fazer diante de sangramentos ou de sua possibilidade, como na prática de esportes, andar de motocicleta, ou na realização de viagens e trilhas, por exemplo.

É comum que as restrições se prolonguem, seja pelas sequelas dos eventos trombóticos, seja pelo próprio tratamento com anticoagulantes, cujo uso pode durar alguns meses ou estar previsto para toda a vida. O tempo de tratamento dependerá da avaliação, por médicos especialistas, de fatores de risco que envolvem desde o número de eventos

a primeira autora não se sentia, como administradora de um grupo, à época, à vontade para realizar uma pesquisa aos moldes mais "sistemáticos", entendendo que poderia gerar constrangimento aos participantes, dado que havia também se apresentado originalmente como médica nos grupos - e algumas das pessoas a ela recorriam com dúvidas que poderiam instituir, ainda que gerando apenas orientações, alguma expectativa compatível com este papel - e o sigilo daí decorrente. Por isso, no lugar de apresentar posts e trechos de falas (o que, sem dúvidas, originaria análises mais abrangentes), optamos por apresentar essas notas observacionais fluidas, sem nomear os grupos. De todo modo, todos têm mais de mil membros, são fechados, têm mediação por administradores, e parecem ter um recorte óbvio de classe e raça - sobretudo aqueles voltados às discussões sobre trombofilia e gestação. O número maior de falas/posts, nos grupos em língua portuguesa, é de mulheres brancas, com acesso seja a serviços de saúde, incluindo planos privados, seja à judicialização da saúde.

5 Sobre essas fotografias e as restrições cotidianas, a primeira autora desenvolve um blog fotográfico aberto autoetnográfico na plataforma Instagram denominado "Vivendo Múltiplos Diagnósticos". O blog encontra-se acessível a partir do endereço: @vivendomultiplos. 
trombóticos, até a coexistência de outras condições que levam ao risco aumentado de trombose.

Nesta primeira via, temos uma narrativa de suporte aos portadores/usuários e é interessante ver postagens comuns sobre uma estética nova a que o corpo (feminino) precisa se encaixar: a existência de manchas roxas em áreas expostas que integram um estigma que cerca o uso de anticoagulantes - a existência de hemorragias ou seu risco iminente. A relação com o tratamento com anticoagulantes dá aos corpos femininos anticoagulados uma feição distante do desempenho esperado ou do "padrão de beleza" atualmente propalado, o que piora naquelas que apresentam também o efeito colateral de queda de cabelo.

Este estigma inclui ainda alterações e/ou aumento do fluxo menstrual, que pode, em algumas mulheres, ser tão intenso que as leva a quadros de anemia. Nesses casos, a restrição cotidiana aumenta expressivamente, sendo por vezes necessário repouso durante toda a época da menstruação, o que torna esse segmento de mulheres mais suscetível às repercussões sociais dos efeitos colaterais de anticoagulantes, como sua demissão dos empregos, algumas vezes relatada nos grupos em língua estrangeira. Em alguns casos, podem ser necessárias transfusões ou mesmo a retirada do útero ou a neutralização de sua camada interna (um procedimento chamado de "ablação do endométrio") ${ }^{6}$.

Há diversas postagens que tematizam a banalização da prescrição de anticoncepcionais e começam a problematizar as demais opções contraceptivas, que não incluem tratamento hormonal e não trariam risco acrescido de trombose, como os preservativos e o DIU de cobre. Na maior parte das vezes, percebemos que definir outra opção, além dos CBH, é reconhecida como missão das mulheres trombofílicas cisgênero. Pouca discussão sobre gênero e diversidade alcança os posts, bem como sobre o uso dos preservativos, ainda que haja alguns posts nos grupos de língua inglesa sobre isso, e neles alguns homens se manifestam a favor de opções geralmente menos interventoras sobre o corpo feminino.

Outro tipo recorrente de postagem versa sobre a segurança da chamada minipílula (CBH que contêm somente derivados sintéticos da progesterona em sua formulação). Sobre seu uso em mulheres trombofílicas, muitos especialistas divergem e geralmente os relatos mencionam que os ginecologistas defendem seu uso, ao passo em que os hematologistas e alguns angiologistas/cirurgiões vasculares a contraindicam. O mesmo ocorre com o DIU de base hormonal.

\footnotetext{
${ }^{6}$ Recentemente, parece estar sendo cunhada uma nova entidade nosológica que expressa a necessidade de consensuar as abordagens médicas do chamado sangramento menstrual intenso (tradução livre de "heavy menstrual bleeding") relacionado ao uso de anticoagulantes. A este respeito, destaca-se uma comunicação de abril de 2018 da Associação Americana de Hematologia, disponível em: http://www.hematology.org/Thehematologist/Diffusion/8467.aspx.
} 
É importante mencionar que, diante de condutas divergentes, as mulheres buscam os grupos como fonte de checagem sobre as orientações médicas. Destacamos a ação de um grupo de ativistas que possui uma página pública no Facebook ("Vítimas de Anticoncepcionais. Unidas a Favor da Vida"), que vem problematizando a discussão das escolhas dos métodos contraceptivos em suas postagens. Este grupo tem conseguido pautar alguns meios de comunicação de grande penetração: um exemplo foi a reportagem de capa do número 877 da Revista Época (2015), com uma das entrevistadas sentada em um banco, com um vestido de gala, as pernas cruzadas, faltando-lhe os dedos dos pés (Figura 1).

Figura 1.

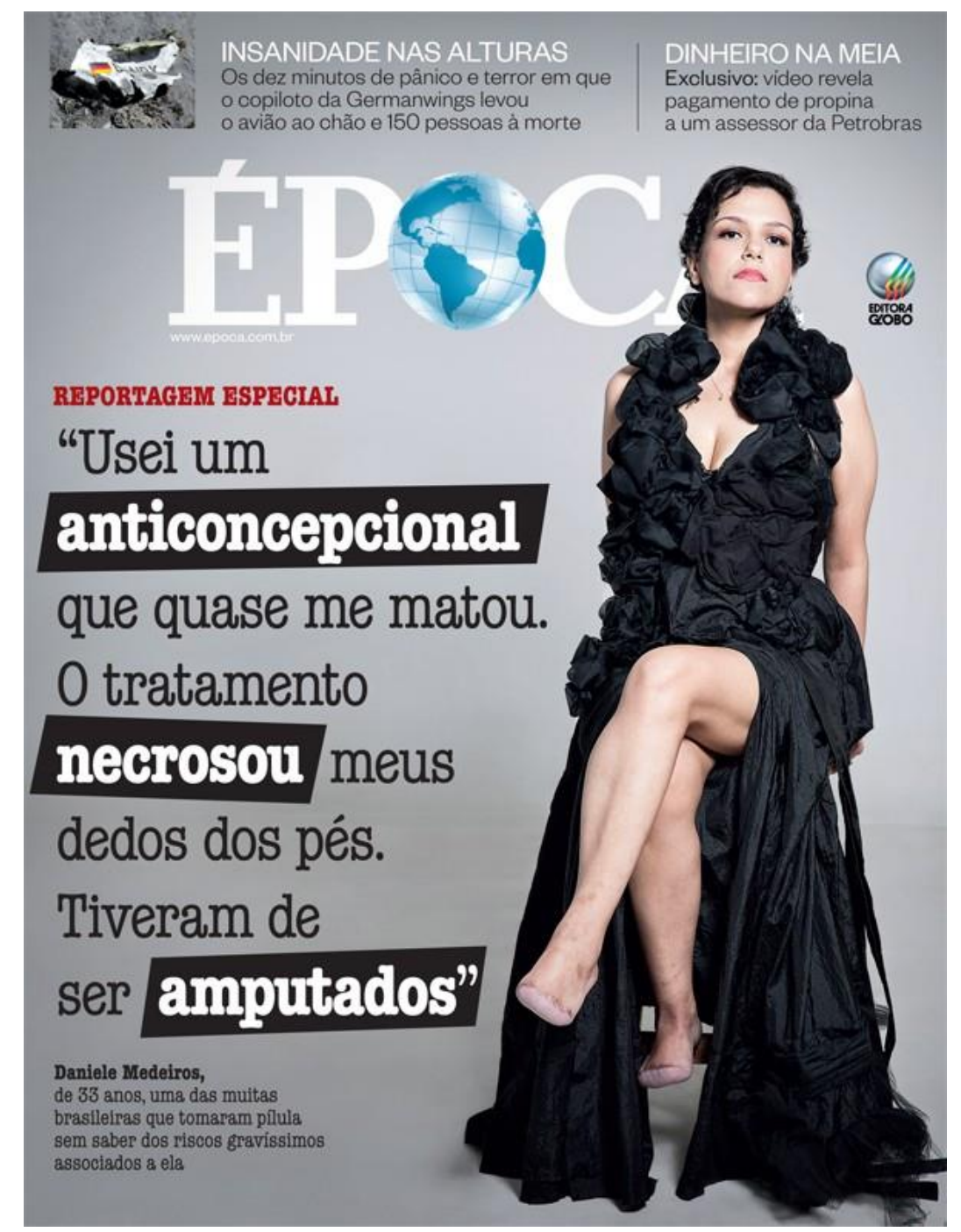

Capa da Revista Época número 877 (abril de 2015).

Entre outras questões, este coletivo apresenta como pauta a introdução de testagem para trombofilias previamente à prescrição de anticoncepcionais. Apesar disso, ainda são poucas as iniciativas de divulgação e difusão científica sobre as trombofilias e, ainda menos numerosas, aquelas que se voltam à problemática do risco acrescido em 
mulheres. Ademais, nas postagens dos grupos nos Brasil, pouco se vê o lugar da equipe generalista na coordenação do cuidado à saúde dessas mulheres, como prevê o SUS e outros sistemas universais ${ }^{7}$.

\section{A SEGUNDA ENTRADA - VIA DOLOROSA E O MILAGRE DA VIDA MEDICALIZADA}

Uma segunda via de entrada nos grupos de Facebook se dá de modo preponderante naqueles que circunscrevem a questão da trombofilia à reprodução (e ao acesso/vivência das TRA). Esses grupos reúnem relatos mais específicos sobre como o diagnóstico de trombofilia levou as mulheres a serem encaminhadas à chamada "clínica de infertilidade", que congrega uma gama de custosas e ainda restritas intervenções tecnológicas sobre a reprodução.

Diante de perda gestacional recorrente, é comum que o/a obstetra realize os testes para trombofilias e, ao menos na medicina privada, é corrente que sejam indicados às mulheres anticoagulantes injetáveis. Eles devem ser usados durante as "tentativas", toda a gestão e, pelo menos, parte do puerpério. Uma parte das portadoras de trombofilia é também encaminhada aos serviços que ofertam TRA. O acesso à enoxaparina sódica, medicamento comumente indicado para as gestantes que têm trombofilia, é um ponto crucial de disputas judiciais.

Em pesquisa de preços realizada na segunda quinzena de dezembro de 2018, verificamos que o menor custo mensal com a enoxaparina fica em torno de $\mathrm{R} \$ 800,00$, se usada a dose preventiva. Caso a mulher já seja usuária de anticoagulantes por tempo indeterminado, deverá utilizar uma dose maior, para a chamada "anticoagulação plena". Nesse caso, uma mulher de $80 \mathrm{~kg}$ usaria, por exemplo, $80 \mathrm{mg}$ de 12/12h, cerca de R\$5.500,00 mensais destinados apenas a custear um medicamento.

Além disso, como mencionado, o acesso às TRA é bastante restrito. Segundo um portal conhecido de divulgação de conteúdo sobre gestação e maternidade, a média de custo de cada tentativa da técnica de fertilização in vitro varia entre $\mathrm{R} \$ 5.000,00$ e $\mathrm{R} \$ 20.000,00^{8}$. Diferentemente dos planos de saúde, os procedimentos de TRA estão disponíveis pelo SUS, porém apresentam barreiras expressivas, como a baixa cobertura de serviços especializados (LOPES, 2018). Se, por um lado, há forte demanda reprimida pela TRA no SUS, por outro lado, o acesso à compra desses serviços restringe-se a uma pequena parcela da população.

\footnotetext{
${ }^{7}$ Esse lugar da equipe generalista é comum em relatos de pessoas do Reino Unido e da Austrália que integram grupos em língua inglesa. Em grupos correlatos em língua portuguesa não percebemos essa frequência.

${ }^{8}$ Portal Gestação Bebê, disponível em https://www.gestacaobebe.com.br/fertilizacao-in-vitro-valor2017/ Acesso em 28 de dezembro de 2018.
} 
A expressão disso nos grupos se dá pela recorrência dos posts sobre como conseguir o remédio na justiça, por exemplo. Os membros se ajudam, orientando-se mutuamente sobre como se dá o passo-a-passo do processo de judicialização para obtenção de enoxaparina. Sobre isso, há um nítido recorte de classe e de raça, pelo menos nessa via. As postagens sobre as técnicas de reprodução assistida são geralmente apresentadas por mulheres brancas e de alta renda, que detêm, no circuito dos grupos específicos sobre reprodução e trombofilia, um vocabulário próprio. Esse léxico é impregnado dos termos médicos da área de TRA, afeito às pessoas que têm acesso suficiente tanto para "comprar o produto" (tecnologia médica), quanto para interpretar e incorporar as informações relativas a esse universo.

É notável que os relatos referentes a esta segunda via atestam a forma traumática com que as perdas gestacionais são vivenciadas e, nestes processos, sobretudo nos grupos em língua portuguesa, pouco são evocados os pais/companheiros/maridos, apesar das ideias de que uma "família completa tem de ter um filho" ou que "uma mulher não é completa se não tiver filhos" estejam subjacentes a várias postagens. Há um silenciamento dos posts que tentam evocar a possibilidade de se optar por não ter filhos ou biologicamente, ou mesmo de não os ter.

Quando a primeira autora mencionou a opção por não ter filhos em uma de suas postagens, os comentários variaram de entender que esta é uma escolha que cabe à mulher, até acusações sobre se tratar de uma covardia. Afinal, não ceder ao clamor da "função natural" de uma mulher, mesmo que por vias tecnológicas caras e muitas vezes arriscadas é, nesse circuito, uma transgressão às regras tácitas que sustentam a existência do próprio grupo.

Isso implica em outros dois silenciamentos importantes: o primeiro é sobre as repercussões da infertilidade sobre a vida das mulheres. Pouco emerge, publicamente, em que medida a vivência ou a busca da maternidade biológica participa do delineamento de suas relações. Geralmente, isso é evocado em trocas de mensagens privadas entre as mulheres. No entanto, nas narrativas públicas ficam patentes a frustração e a intensa angústia que é trazida pelas barreiras de fertilidade.

Por um lado, esses grupos operam como uma ferramenta notável de suporte mútuo para mulheres que se dedicam às tentativas de engravidar. São espaços importantes para se trocar sentimentos sobre os processos de abortamento, que é ainda um tabu. Por outro lado, no mais das vezes, a centralidade dos posts reside nos procedimentos biotecnológicos reprodutivos médicos, restando apagada a abordagem clínica mais ampla da angústia, por exemplo.

Sabe-se que o processo de perda gestacional pode ser bastante traumático e, diante de situações críticas como as descritas, é indicado que a pessoa e/ou a família seja 
encaminhada a serviços de atenção psicossocial (MARQUES; MORAIS, 2018). No entanto, isso não alça relevância nos relatos desse circuito. O registro fotográfico de ultrassonografias e dos hematomas causados pelas injeções de anticoagulantes nas barrigas é tema comum das fotos veiculadas. Já os relatos sobre recorrerem a outra dimensão clínica, como a psicoterapia, para abordarem os traumas advindos das dificuldades reprodutivas, não são comumente apresentados.

O segundo processo de silenciamento é aquele relacionado aos riscos inerentes à condição de trombofílica que existem para além da gravidez. Entre as mulheres que se descobriram trombofílicas justamente por conta de perdas gestacionais e que não tiveram nenhum evento trombótico até então, é comum um tipo de relato: comentam que o médico thes disse que trombofilia é algo com que se devem preocupar somente na gestação.

Esta minimização está presente também no apagamento dos riscos do uso de terapia hormonal inerente a algumas das TRA, mesmo em trombofílicas. É importante assinalar que o óbito materno e outras complicações obstétricas rondam o universo das portadoras (FONSECA, 2012) e, no entanto, isso não é algo a ser mencionado nesses grupos. Por outro lado, foram observadas postagens que indagavam sobre a necessidade do parto cesáreo, recorrente entre essas mulheres: os posts mostram que a escolha do tipo de parto parece depender da equipe assistente, apesar de, na literatura médica, a cesariana estar relacionada ao aumento do risco de eventos trombóticos.

Nessa via de entrada, a narrativa sobre os riscos é suplantada pela perspectiva performática de atingir a meta de ser mulher-boa-mãe. Gerar e manter um bebê até o fim da gravidez parece ser fulcral nesses relatos. Uma prática cada vez mais recorrente nesse circuito diz respeito ao registro fotográfico do milagre da vida (medicalizada): como mencionado, em muitos dos protocolos de trombofilia e gestação, há a indicação de uso de anticoagulantes injetáveis, cuja administração comumente na barriga, no mínimo uma vez ao dia, implica em nódulos, manchas roxas e um processo doloroso de mudança do corpo feminino. Aqui, o estigma dá lugar à narrativa sacrificial do "ser mãe" que se espera seja coroada pela imagem de uma analogia ao Menino Jesus em uma manjedoura, rodeado por todas as seringas utilizadas no processo de concepção/gestação da criança denominada comumente de "meu milagre" (como na Figura 2).

\section{Figura 2}




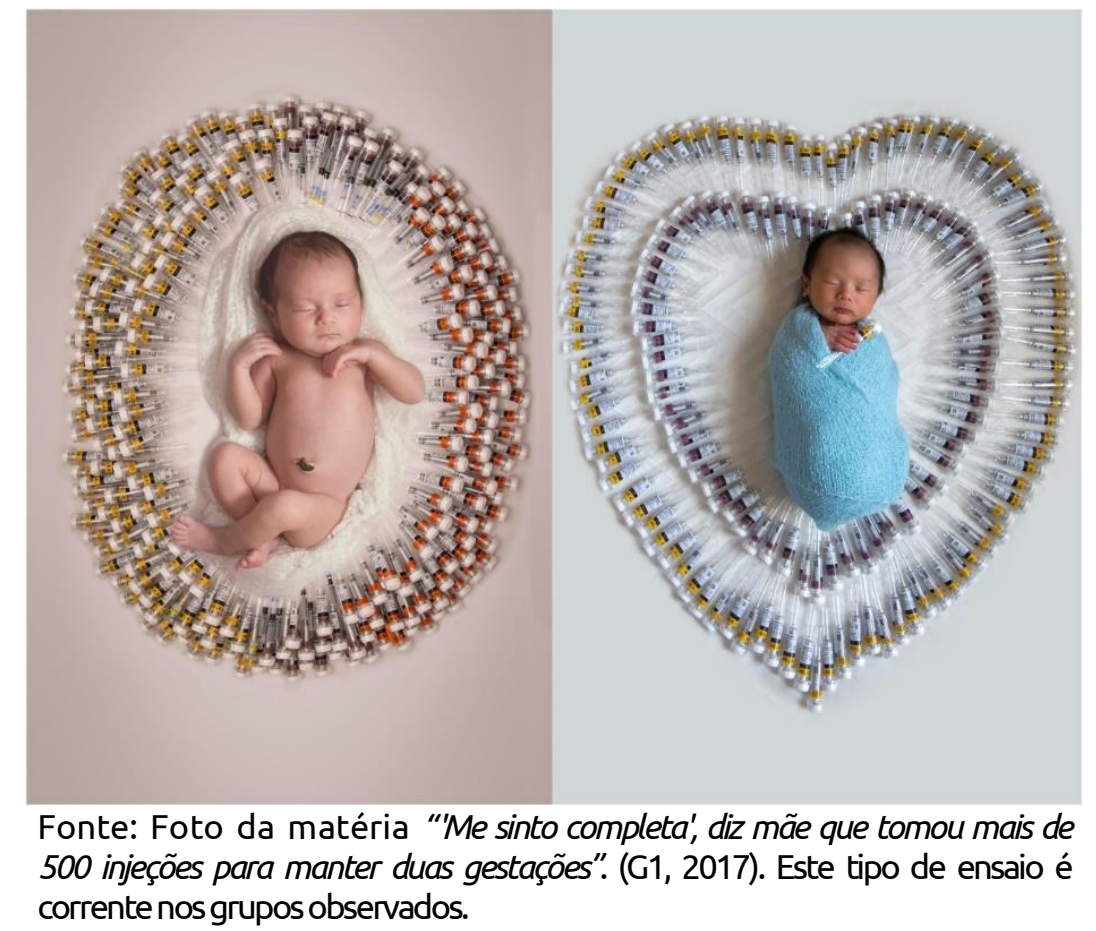

\section{CONSIDERAÇÕES FINAIS}

A análise das implicações das marcas de gênero para a contracepção e a reprodução contribui para reflexões sobre família e direitos sexuais e reprodutivos. Nesta direção, investigar as pouco estudadas especificidades de mulheres portadoras de trombofilia parece trazer à tona mecanismos de medicalização do corpo feminino, acentuados neste grupo.

As observações das postagens na rede Facebook e o relato de cunho autoetnográfico ajudam a delinear uma problemática que revela, seja pelo que está explícito, seja pelos silenciamentos, a circunscrição da vida à esfera médica (CONRAD, 2007) e o controle dos corpos femininos. Neste jogo de explicitação, relação com as tecnologias médicas e apagamento de processos, reside a peculiaridade do discurso médico, que constrói e é construído pela mercantilização da vida, e que tem nas desigualdades de gênero um motor fundamental (SANCHEZ, 2008).

Questões centrais de ambas as vias descritas parecem ainda ser pouco debatidas na esfera pública: seja a banalização do uso de $\mathrm{ABH}$ e a baixa autonomia feminina sobre a escolha dos métodos contraceptivos; sejam as barreiras ao acesso a TRA e/ou a submissão de mulheres ao papel materno de reprodução biológica, frente a problemas de fertilidade. Ambas as vias denotam experiências de sofrimento de corpos femininos dolorosamente medicalizados. Se na primeira via a questão dos riscos em saúde ajuda a circunscrever a narrativa, na segunda os riscos sobre a gravidez sofrem apagamento, frente à dimensão sacrificial da maternidade. 
Neste trabalho, não analisamos os processos de medicalização que também cercam a construção e o controle dos corpos masculinos, com seus modos e efeitos peculiares. Também não observamos relatos da vivência da maternidade de mulheres trans, tampouco relatos dos riscos referentes ao uso de terapia hormonal usada no processo de redesignação de gênero de mulheres e homens trans. Estas são questões pertinentes para a saúde pública, porém não vocalizadas ou, possivelmente, invisibilizadas, como acontece com muitas das questões de saúde desta população (POPADIUK; OLIVEIRA; SIGNORELLI, 2017). Além disso, cabe destacar que o uso crescente de derivados de testosterona, tanto em homens, quanto em mulheres (MORAES; CASTIEL; RIBEIRO, 2015), aponta para possíveis repercussões na abordagem de portadores de trombofilias.

Por fim, acreditamos que as técnicas de pesquisa utilizadas neste trabalho possam contribuir com abordagens úteis para a análise e formulação de políticas de enfrentamento às desigualdades de gênero e raça, aí incluídas as de saúde.

\section{REFERÊNCIAS}

BANK, Ivan et al. Social aspects of genetic testing for Factor V Leiden mutation in healthy individuals and their importance for daily practice. Thrombosis Research, v.113, n.1, p. 7-12, 2004.

BERMAN, Ruth. Do dualismo de Aristóteles à Dialética Materialista: a transformação feminista da ciência e da sociedade. In: JAGGAR, Alison; BORDO, Susan (Org.). Gênero, Corpo, Conhecimento. Rio de Janeiro, Rosa dos Tempos, 1997.

BRASIL. Ministério da Saúde. Secretaria de Atenção à Saúde. Departamento de Ações Programáticas Estratégicas. Política nacional de atenção integral à saúde da mulher: princípios e diretrizes. Ministério da Saúde, Secretaria de Atenção à Saúde, Departamento de Ações Programáticas Estratégicas. Brasília: Ministério da Saúde, 2004.

CASTIEL, Luis D.; PÓVOA, Eduardo C. Medicina Baseada em Evidências: novo paradigma assistencial e pedagógico? Interface (Botucatu), v.6, n.11, p.117-121, 2002.

CONRAD, P. The Medicalization of Society: on the transformation of human conditions into treatable disorders. Johns Hopkins University Press, 2007.

COSTA, Tonia et al. Naturalização e medicalização do corpo feminino: o controle social por meio da reprodução. Interface (Botucatu), v.10, n.20, 2006, p.363-380.

DUTRA, Gabriella S. 0. Corpos e identidades que escapam: uma análise autoetnográfica da mulher deficiente ou aquilo que 0 Direito não vê. Trabalho apresentado na $31^{\text {a }}$ Reunião Brasileira de Antropologia. dezembro de 2018, Brasília/DF. Disponível em https://www.31rba.abant.org.br/simposio/view?ID SIMPOSIO=86 Acesso em 15 ago 2019.

FONSECA, Ana Glória. As trombofilias hereditárias na grávida: do risco trombótico ao sucesso da gravidez. Acta Med Port, v.25, n.6, p.433-441, 2012. 
G1. 'Me sinto completa', diz mãe que tomou mais de 500 injeções para manter duas gestações. 12 mai 2017. Disponível em: <https://g1.globo.com/sp/mogi-das-cruzes-suzano/noticia/me-sinto-completa-dizmae-que-tomou-mais-de-500-injecoes-para-manter-duas-gestacoes.ghtml>. Acesso em 08 out 2017.

GIFFIN, Karen. Pobreza, desigualdade e equidade em saúde: considerações a partir de uma perspectiva de gênero transversal. Cad. Saúde Pública, v. 18, p.103-112, 2002.

GUIMARÃES, Sabrina P et al. Mutações predisponentes à trombofilia em indivíduos de Minas Gerais Brasil com suspeita clínica de trombose. Rev. Bras. Hematol. Hemoter., v. 31, n. 1, p.19-24, 2009.

HARAWAY, Donna J. Situated Knowledges: the science question in feminism and the privilege of partial perspective. In.:

Routledge, 1991. p.183-202. Simians, Cyborgs and Women: the reinvention of nature. New York:

LIMA, Jorge; BORGES, Augusta. Rastreio de Trombofilias. Boletim da SPHM. v.27, n.4, p.5-11, 2012.

LOPES, Laís. Qual o futuro dos direitos sexuais e reprodutivos nas relações familiares? In: MONICA, Eder Fernandes; MARTINS, Ana Paula Antunes. Qual o futuro da sexualidade no direito?. Rio de Janeiro: PPGSD-UFF/Bonecker, 2018. p.171-193.

MARQUES, Patrícia Pinheiro; MORAIS, Normanda Araujo. A vivência de casais inférteis diante de tentativas inexitosas de reprodução assistida. Av. Psicol. Latinoam., v. 36, n. 2, p. 299-314, 2018.

MORAES, Danielle Ribeiro de; CASTIEL, Luis David; RIBEIRO, Ana Paula Pereira da Gama Alves. "Não" para jovens bombados, "sim" para velhos empinados: 0 discurso sobre anabolizantes e saúde em artigos da área biomédica. Cad. Saúde Pública, v.31, n.6, p.1131-1140, 2015.

MORAES, Danielle Ribeiro de. Entre Tiro, Porrada e Bomba: esteroides anabolizantes androgênicos, gerencialismo arriscado e os discursos médicos moralizantes. Tese. Doutorado em Saúde Pública. Escola Nacional de Saúde Pública, FIOCRUZ, 2016.

POLITI, Cecilia et al. Gender Medicine: an up-date. Italian Journal of Medicine, v. 7, p.96-106, 2013.

POPADIUK, Gianna Schreiber; OLIVEIRA, Daniel Canavese; SIGNORELLI, Marcos Claudio. A Política Nacional de Saúde Integral de Lésbicas, Gays, Bissexuais e Transgêneros (LGBT) e 0 acesso ao Processo Transexualizador no Sistema Único de Saúde (SUS): avanços e desafios. Ciênc. saúde coletiva, v.22, n.5, p.1509-1520, 2017.

REVISTA ÉPOCA. Quando a pílula anticoncepcional é a pior escolha. 27 mar 2015. Disponível em <http://epoca.globo.com/vida/noticia/2015/03/quando-pilula-anticoncepcional-e-pior-escolha.html>.

Acesso em 08 out 2017.

SÁNCHEZ, D. El discurso médico, piedra angular de la construcción de las relaciones de género en la época contemporánea. Asclepio. Revista de Historia de la Medicina y de la Ciencia, Madrid, v.LX, n.1, p.63-82, 2008.

SOLIGO, Adriana, DGS et al. Prevalence of Thrombophilic Factors in Infertile Women. Revista Brasileira de Ginecologia e Obstetrícia, v. 29, n. 5, p.235-240, 2007. 
VERNON, Erin; HIEDEMANN, Bridget; BOWIE, Bonnie. Economic Evaluations of Thrombophilia Screening Prior to Prescribing Combined Oral Contraceptives: A Systematic and Critical Review. Appl Health Econ Health Policy, 2017.

VIEIRA, Elisabeth. M. A medicalização do corpo feminino. Rio de Janeiro: Fiocruz, 2003.

Recebido em 28 de dezembro de 2018. Aprovado em 20 de agosto de 2019. 